\title{
CITOLOGIA DE IMPRESSÃO DA SUPERFÍCIE OCULAR DE CÃES INFECTADOS NATURALMENTE POR Leishmania (L.) chagasi
}

\section{Impression cytology of ocular surface of naturally infected dogs by Leishmania (L.) chagasi}

\author{
ANDRADE, A.L."; SANTO, E.F.E.2; SAKAMOTO, S.S².; LIMA, L.K.F.2; \\ LUVIZOTTO, M.C.R. ${ }^{3}$
}

\author{
${ }_{1}^{1}$ Médico Veterinário, MSc. Dr - Cirurgia de Pequenos Animais, oftalmologia. \\ 2 Médico Veterinário - Programa de Pós Graduação em Ciência Animal - UNESP \\ ${ }^{3}$ Departamento de Clínica, Cirurgia e Reprodução Animal - UNESP
}

Endereço para correspondência: Alexandre Lima de Andrade: landrade@fmva.unesp.br

\section{RESUMO}

Os cães domésticos são considerados o reservatório principal da Leishmania infantum (= Leishmania $L$. chagasi), o agente causal da Leishmaniose Visceral Canina (LVC). Sendo assim, a LVC tem uma importância particular não somente para os clínicos veterinários, mas também à saúde pública. Entre sinais sistêmicos, incluem-se as alterações oculares com blefarite, conjuntivite, ceratoconjuntivite e ceratouveite. $O$ objetivo deste trabalho foi avaliar os distúrbios da superfície ocular de cães com LVC com ou sem sinais oculares por meio de citologia de impressão. Este método tem caráter não-invasivo, induz mínimo trauma e boa qualidade das amostras. Os animais foram divididos em três grupos: G1, constituído por 15 animais positivos e apresentando sinais oculares de uveíte; G2, constituído por 15 animais positivos e sem sinais oculares de uveíte e G3, constituído por 5 animais sadios. O material ocular foi coletado e processado, sendo subseqüentemente analisado obtendo-se informações de cada grupo. Os animais com sinais oculares e sistêmicos apresentaram elevado infiltrado de polimorfonucleares e grande quantidade de debris celulares e muco em comparação aos animais do grupo sem sinais oculares e grupo controle. Conclui-se que a citologia de impressão de cães com sinais oculares pode ser útil no diagnóstico presuntivo da doença, no entanto, os exames, parasitológico e sorológico, são essenciais no diagnóstico da LVC.

Palavras-chave: cães, Leishmaniose Visceral Canina, olho, técnicas citológicas, uveíte

\section{ABSTRACT}

Domestic dogs are considered to be the principal host reservoir of Leishmania infantum (= L. chagasi), the causative agent of Canine Visceral Leishmaniasis (CVL) Hence, canine leishmaniasis has a particular importance not only for the clinical veterinarians, but also to public health. Among systemic signs includes ocular alterations as blepharitis, conjunctivitis, keratoconjunctivitis and keratouveitis. The aim of this study was to evalutate ocular surface disturbance in dogs with CVL whether with or without ocular signs accessed by impression cytology. This method has a non-invasive character, minimum induced trauma exam and good sample quality. Animals were divided in 3 groups: G1, consisting of 15 positive animals for CCL and showing signs of ocular uveitis; G2, consisting of 15 positive animals for CCL and without ocular signs uveitis and G3, consisting of 5 healthy animals. The ocular material was collected and processed; subsequently was carried out analysis to obtain information from each group. Animals with ocular and sistemic signs showed I high infiltrated polimorphonuclear cells and great amount of cellular debris with mucus in comparison to CVL carrying animals without ocular signs and the control group. In conclusion, impression cytology of dogs with ocular signs as uveitis caused leishmaniasis can be useful as CVL presuntive diagnostic although the parasitological and serological exams are essential for CVL diagnosis.

Key words: Canine Visceral Leishmaniasis, dogs, eye, impression cytology, uveitis 


\section{INTRODUÇÃO}

A leishmaniose visceral é uma antropozoonose causada por um protozoário do gênero Leishmania, cuja transmissão entre os hospedeiros vertebrados, ocorre pela picada do flebotomíneo Lutzomyia longipalpis infectado (Ribeiro, 1997; Santa Rosa e Oliveira, 1997; Pocai et al., 1998). Do ponto de vista epidemiológico, a doença canina é considerada mais importante que a doença humana, pois, além de ser mais prevalente, apresenta grande contingente de animais assintomáticos albergando parasitos na derme (Marzochi et al., 1985; Santa Rosa e Oliveira, 1997).

O primeiro caso de leishmaniose visceral canina no Estado de São Paulo foi diagnosticado no município de Araçatuba, no Hospital Veterinário "Luiz Quintiliano de Oliveira" da Faculdade de Medicina Veterinária - UNESP, no mês de maio de 1998. Desde então, o número de casos caninos de leishmaniose visceral nesta região vem aumentando significativamente, e de acordo com os dados da Direção Regional de Saúde, vários municípios da região já apresentaram casos confirmados da doença. No estado de São Paulo, no período de 1999 a 2000, 30 casos humanos foram confirmados, sendo que 0 município de Araçatuba concentra 83,3\% dos casos.

Os animais acometidos por leishmaniose visceral podem apresentar uma grande variedade de manifestações clínicas sistêmicas incluindo as alterações oculares (Marzochi et al., 1985; Font et al., 1996; Garcia-Alonso et al., 1996; Ciaramella et al., 1997; Blavier et al., 2001). Algumas das manifestações oftálmicas mais importantes da doença são: blefarite, conjuntivite, ceratoconjuntivite e ceratouveíte, ocorrendo nesta última, uma predisposição à existência de lesões no segmento anterior do olho, e sua persistência, mesmo nos casos onde 0 tratamento específico é utilizado (GarciaAlonso et al., 1996).

A superfície ocular tem sido extensivamente estudada no homem, principalmente nos casos de deficiência límbica severa causada por queimaduras químicas ou térmicas (Kim et al., 2000). Um dos métodos de estudo destes distúrbios desta natureza é a citologia de impressão, que se constitui em um método para obtenção de células dos epitélios conjuntivais e corneais (Egbert et al., 1977). Tal método apresenta como vantagens a colheita simples do material de estudo, o caráter não invasivo e o mínimo trauma induzido (Barros et al., 2001). Representa, ainda, uma alternativa em relação à citologia obtida por raspados da superfície ocular, além de garantir uma melhor qualidade das amostras (Dart, 1997). Ressalta-se também, que o exame fornece a obtenção de informações relativas à topografia, ao padrão celular e relação entre células epiteliais e outros componentes celulares (Tseng, 1985). Esta técnica auxilia o entendimento e direciona 0 tratamento das afecções da superfície ocular, pois permite a análise do grau de metaplasia escamosa, contagem do número de células caliciformes em casos de olho seco, hipovitaminose A e deficiência límbica corneal (Síndrome de Stevens-Johnson, penfigóide ocular e queimadura ocular) (Gomes, 2000). Utilizase, ainda, como método de análise microbiológica viral (Thiel, 1997; Jackson e Perrigin, 1999). Bolzan et al. (2003), descreveram os aspectos da citologia de impressão em cães sem alterações da superfície ocular, e concluíram pela viabilidade do método em cães, indicandoo, assim como no homem, em detrimento aos raspados e biópsias.

Não foram encontrados dados de citologia de impressão da superfície ocular de cães com Leishmaniose Visceral. Embora o escopo do estudo não seja a substituição de exames mais específicos como, por exemplo, a sorologia, as informações que possam ser obtidas 
quanto ao padrão celular observado em casos positivos de leishmaniose, poderá recomendar esta análise como indicador indireto de diagnóstico. Sendo assim, este trabalho teve por objetivo verificar as alterações da superfície ocular em cães com diagnóstico confirmado de LVC, com ou sem sinais oculares, por meio da citologia de impressão.

\section{MATERIAL E MÉTODOS}

Foram utilizados 35 cães da área endêmica de Araçatuba (SP) para leishmaniose visceral oriundos do Centro de Controle de Zoonoses de Araçatuba e cinco cães da cidade de São Paulo (área não endêmica), adquiridos entre 2005 e 2006. Os cães foram divididos em três grupos:

- GRUPO 1 (G1): 15 cães sintomáticos, portadores de leishmaniose visceral (com resultado positivo aos exames sorológico e/ou citológico de linfonodo), com sinais clínicos oculares de uveíte;

- GRUPO 2 (G2): 15 cães assintomáticos ou oligossintomáticos, portadores de leishmaniose visceral (com resultado positivo aos exames sorológico e/ou citológico de linfonodo), sem sinais clínicos oculares de uveíte;

- GRUPO 3 (G3): 5 cães sadios (com resultado negativo aos exames sorológico e/ou citológico do linfonodo) oriundos de área não endêmica.

O diagnóstico de leishmaniose foi estabelecido por meio do exame clínico, exame citológico da punção aspirativa por agulha fina de linfonodo, além de exame sorológico (ELISA). Os animais foram incluídos nos grupos descritos acima, após exames clínicos de rotina (positivos nos exames sorológicos e/ou citológico) e oftalmológico completo na busca de alterações oftálmicas compatíveis com uveíte. Os dados foram anotados em fichas individuais.

Citologia de impressão da superfície ocular.

Ao final do exame oftálmico, os animais receberam sobre a superfície ocular uma gota de colírio anestésico a base de cloridrato de proximetacaína (Anestalcon $0,5 \%{ }^{\circledR}$, Alcon), para dessensibilização da mesma. Em seguida, foi aplicada uma tira assimétrica do papel de filtro com o poro de $0,45 \mu \mathrm{m}$ (Millipore Corporation), cortado nas dimensões aproximadas de $5 \mathrm{~mm}$ de largura $\times 7 \mathrm{~mm}$ de altura, com ápice, base e abertura lateral com auxílio de uma pinça com extremidade suave, sobre a conjuntiva bulbar nas regiões de 9 e 12 horas em analogia a um relógio. A tira de papel foi pressionada por alguns segundos sobre a área a ser estudada (2 a 5 segundos em média) em toda a sua extensão para garantir uma boa colheita de células. Em seguida, o papel foi removido com a mesma pinça, por meio de uma manobra de "peeling" (Figura 1).

Após a colheita, o papel foi colocado sobre uma lâmina de vidro limpa e fixado em uma solução previamente preparada contendo: $100 \mathrm{ml}$ álcool etílico a $70 \%, 5 \mathrm{ml}$ de ácido acético glacial e $5 \mathrm{ml}$ de formaldeído a 37\%. A técnica de coloração empregada baseou-se na técnica descrita por Martinez et al. (1995) e Barros et al. (2001), que se utiliza do ácido periódico de Schiff (PAS), hematoxilina e Papanicolau modificado. Após a coloração o papel foi montado em lâmina de vidro com a face que esteve em contato com superfície ocular voltada para cima, e por fim, selado por lamínula e resina sintética. A leitura foi feita em microscópio óptico de luz. Os aspectos estudados foram: 1) amostra considerada adequada: $30 \%$ da extensão do papel com material; 2) quantidade de células; 3) qualidade da coloração; 4) disposição e forma das células (agrupadas e dispersas); 5) células epiteliais (extratos: superficiais, intermediárias e basais); 6) presença de células caliciformes; 7) 
Material extracelular e do fundo (debris celulares e muco); 8) presença de polimorfonucleares; 9) presença de mononucleares e 10) preservação das características das células.

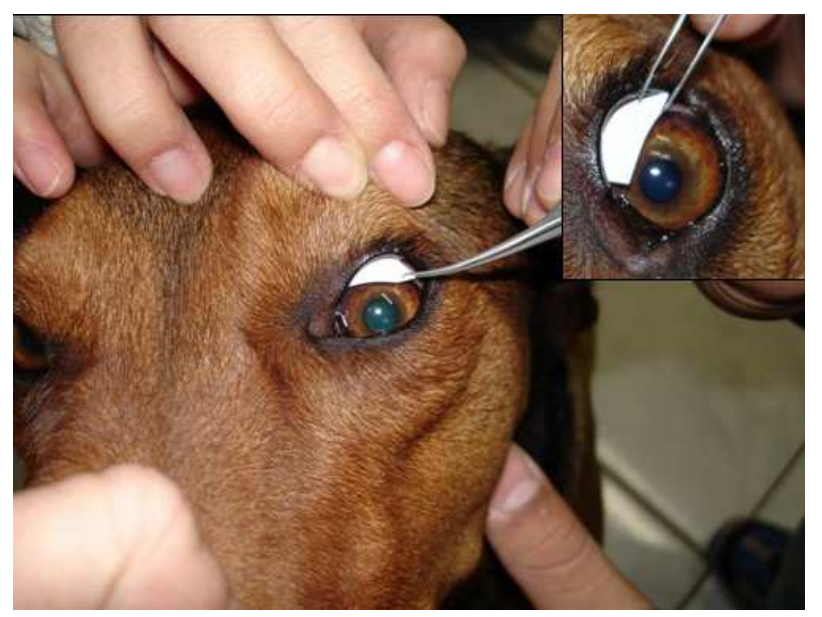

Figura 1 - Imagem fotográfica do procedimento de colheita de células da conjuntiva bulbar por meio de citologia de impressão. Detalhe: "peeling" após compressão do papel sobre a conjuntiva.

\section{RESULTADOS E DISCUSSÃO}

Não se encontraram dificuldades na obtenção do material para a pesquisa proposta, pois a mesma foi conduzida em uma região endêmica para a leishmaniose, onde o número de animais recolhidos pela o Serviço de Vigilância Epidemiológica da cidade é muito grande.

A citologia tem sido usada nas diversas especialidades médicas como método diagnóstico principalmente na ginecologia, no diagnóstico de doenças malignas do colo uterino; na hematologia, no diagnóstico de anemias e leucemias, e nas doenças infecciosas, principalmente nas meningites, através do estudo do fluido cerebral, com grande importância clínica na elucidação diagnóstica e no prognóstico (Bezerra et al., 2003). A citologia de impressão da conjuntiva ocular é um método útil, não invasivo, de avaliação de lesões oculares, já bem estabelecidos entre os oftalmologistas (Rocha et al., 2002). O material obtido possibilitou colher dados que permitem uma suspeita diagnóstica da doença em questão. Vale salientar que nesse período em que a pesquisa se desenvolveu, não foram encontrados trabalhos versando sobre o tema em animais de companhia.

Os sinais clínicos sistêmicos mais observados nos animais do G1 foram linfadenomegalia e seborréia seca. No entanto, metade dos animais do G2, embora tivesse positividade nos exames sorológicos e/ou de punção do linfonodo, eram assintomáticos.

No que se refere à colheita do material pela impressão celular em papel acima descrito, não se encontraram óbices em fazê-la. Os animais toleraram bem tal manobra que era realizada após dessensibilização da superfície ocular com colírio anestésico. Tomou-se cuidado em não colocar o papel logo após a instilação do colírio, uma vez que a adesão celular no papel é prejudicada quando o papel de filtro entra em contato com a lágrima e/ou colírios instilados (Barros et al., 2001).

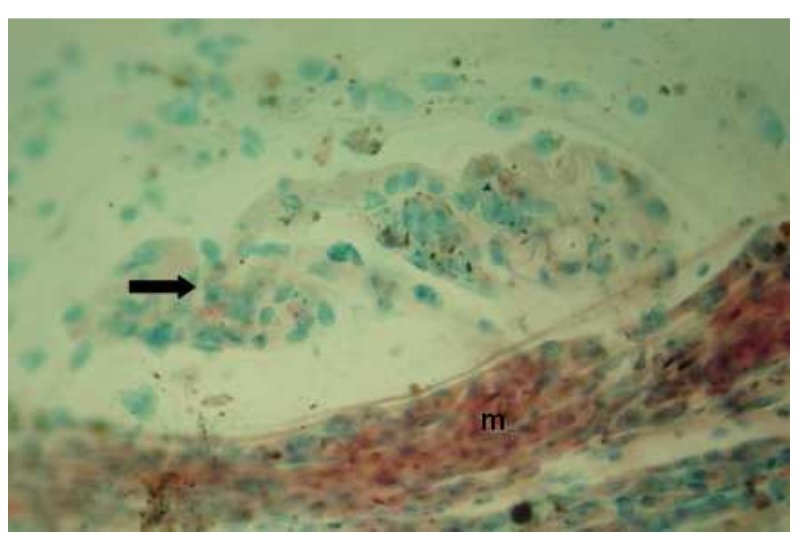

Figura 2 - Imagem fotográfica da citologia de impressão do animal do G1. Observam-se células superficiais (seta), intermediárias e basais e presença de muco $(\mathrm{m})(100 \mathrm{X})$.

A técnica de coloração foi previamente testada em material obtido em outros animais que não foram incluídos nesse estudo, e não se encontraram dificuldades quanto à sua realização. O material colhido foi corado em um só momento, o que minimizou e otimizou os custos desse procedimento. 
O material obtido de todos os animais ocupou mais de $80 \%$ do papel de filtro, o que leva a concluir que todas as amostras foram consideradas adequadas. Nos animais dos três grupos foram observadas células superficiais dispersas e agrupadas ao longo do papel analisado. Porém, as células orangeofílicas (superficiais), foram mais observadas nos animais do G1, que eram portadores de sinais clínicos oculares de uveíte e ceratoconjuntivite seca (CCS) associados. Nesses mesmos animais, foi observada grande quantidade de muco, debris celulares, polimorfonucleares e poucas células caliciformes, que impediu a identificação de células secretórias caliciformes como era de se esperar. Tais achados são observados freqüentemente em distúrbios dessa natureza (Barros et al., 2001, Slatter, 2007).

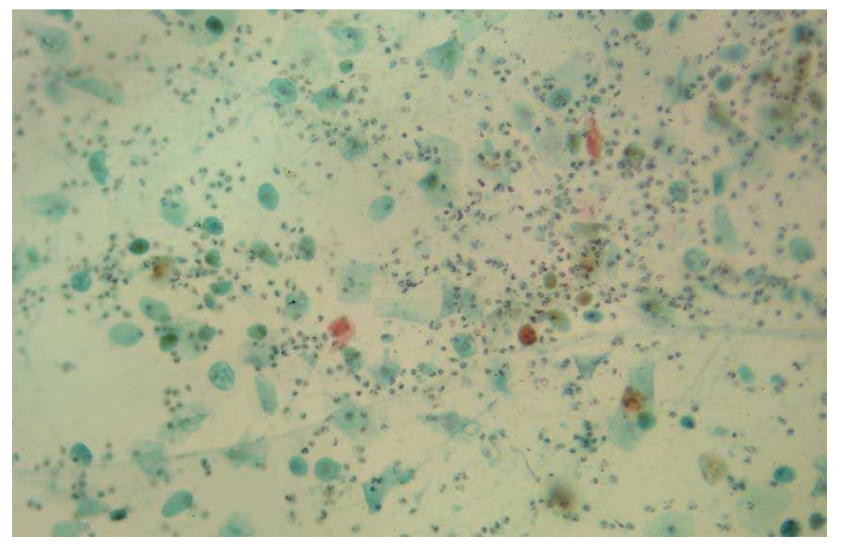

Figura 3 - Imagem fotográfica da citologia de impressão de um animal do G1. Observam-se células intermediárias e basais ainda, infiltrado polimorfonuclear (100X).

A ausência de células caliciformes pode também ser esperada diante da falta de condições ambientais para a normal proliferação das mesmas (Barros et al., 2004). Há relatos de que superfície da conjuntiva alterada freqüentemente é coberta por células epiteliais com metaplasia escamosa, que inclui importante redução ou ausência da população de células caliciformes, como em casos de síndrome de Steven-Johnson e CCS.
Ressalta-se que alguns animais apresentavam CCS e intenso eritema conjuntival. No entanto, não foi possível visualizar formas amastigotas da Leishmania spp, como se pode observar em exames citológicos.

A tabela 1 apresenta os dados individuais relativos aos achados clínicos, oculares e da citologia de impressão. Os achados citopatológicos encontrados nos animais do G1 (cursando uveíte), foram em maior contingente comparativamente aos encontrados nos animais do G2 e G3. Em alguns animais do grupo $\mathrm{G} 1$, foi ainda observada a presença de mononucleares, representados por linfócitos e plasmócitos (figuras 2 e 3). Um fenômeno descrito como emperipolese foi também observado em alguns animais desse grupo, principalmente quando havia grande quantidade de células inflamatórias e células da superfície ocular no campo estudado. Houve diferença dos parâmetros analisados entre os animais do G2 e G3. Neste último, observou-se apenas a presença de células intermediárias e basais e em um dos animais (animal 1) observouse a presença de polimorfonucleares. Nos animais do G2, a presença deste tipo celular foi evidenciada em 53,3\% dos animais. Mas há que se considerar que o número de animais incluídos no G2 era maior do que o número de animais do G3. Os debris celulares e muco raramente foram encontrados nos animais do G2. Salienta-se que tais achados foram evidentes em todos os animais do G1, e que impediu uma melhor avaliação dos achados citológicos encontrados nesses animais. Salienta-se que os achados encontrados nos animais do G3 também foram encontrados por Bolzan et al. (2003) ao estudarem a conjuntiva bulbar de cães sadios pelo mesmo método.

Acredita-se que a repetibilidade dos achados citopatológicos nos animais do G1 nos permita inferir que um padrão 
Tabela 1 - Dados referentes aos sinais clínicos sistêmicos, sinais oculares e achados citopatológicos empregando-se a citologia de impressão da conjuntiva bulbar de cães sintomáticos com uveíte, assintomáticos e oligossintomáticos sem uveíte e sadios.

\begin{tabular}{|c|c|c|c|c|}
\hline Grupos & Animais & Sinais Clínicos Sistêmicos & Sinais Oculares & $\begin{array}{l}\text { Achados na citologia } \\
\text { de impressão }\end{array}$ \\
\hline \multirow{15}{*}{ G1 } & 1 & $\begin{array}{l}\text { Onicogrifose, lesões cutâneas } \\
\text { ulcerativas difusas, seborréia } \\
\text { seca difusa }\end{array}$ & $\begin{array}{c}\text { Quemose e } \\
\text { edema de íris e } \\
\text { miose }\end{array}$ & M. DC, PMN, ER \\
\hline & 2 & $\begin{array}{l}\text { Linfadenomegalia, } \\
\text { onicogrifose, lesões cutâneas } \\
\text { ulcerativas difusas }\end{array}$ & $\begin{array}{l}\text { Quemose, flare e } \\
\text { edema de íris }\end{array}$ & CS, M. DC, PMN, ER \\
\hline & 3 & $\begin{array}{c}\text { Esplenomegalia, onicogrifose e } \\
\text { linfadenomegalia }\end{array}$ & $\begin{array}{c}\text { Quemose, flare e } \\
\text { edema de íris }\end{array}$ & CS, M. DC, PMN, ER \\
\hline & 4 & $\begin{array}{l}\text { Esplenomegalia, } \\
\text { linfadenomegalia e } \\
\text { onicogrifose }\end{array}$ & $\begin{array}{c}\text { Hiperemia } \\
\text { conjuntival, } \\
\text { edema de íris e } \\
\text { flare }\end{array}$ & CS, M, DC \\
\hline & 5 & $\begin{array}{c}\text { Onicogrifose, esplenomegalia e } \\
\text { linfadenomegalia }\end{array}$ & $\begin{array}{l}\text { Miose, edema de } \\
\text { íris e flare }\end{array}$ & M. DC, PMN, ER \\
\hline & 6 & $\begin{array}{c}\text { Esplenomegalia, } \\
\text { linfadenomegalia e lesões } \\
\text { cutâneas ulcerativas difusas }\end{array}$ & $\begin{array}{l}\text { CCS, quemose, } \\
\text { edema de íris e } \\
\text { flare }\end{array}$ & $\mathrm{CS}, \mathrm{M}, \mathrm{MN}$ \\
\hline & 7 & $\begin{array}{c}\text { Esplenomegalia, oligúria e } \\
\text { onicogrifose }\end{array}$ & $\begin{array}{l}\text { CCS, quemose, } \\
\text { edema de íris e } \\
\text { flare }\end{array}$ & CS, M. DC, PMN, ER \\
\hline & 8 & $\begin{array}{c}\text { Esplenomegalia, lesões } \\
\text { cutâneas ulcerativas difusas e } \\
\text { oligúria }\end{array}$ & $\begin{array}{l}\text { CCS, miose e } \\
\text { flare }\end{array}$ & CS, M. DC, PMN, ER \\
\hline & 9 & $\begin{array}{l}\text { Linfadenomegalia, onicogrifose } \\
\text { e vômitos e diarréia crônica }\end{array}$ & $\begin{array}{l}\text { CCS, miose, } \\
\text { ceratite } \\
\text { ulcerativa e flare }\end{array}$ & CS, M. DC, PMN, ER \\
\hline & 10 & $\begin{array}{c}\text { Seborréia seca difusa, oligúria } \\
\text { e lesões cutâneas ulcerativas } \\
\text { difusas }\end{array}$ & $\begin{array}{l}\text { CCS, edema de } \\
\text { íris e flare }\end{array}$ & CS, M. DC, PMN, ER \\
\hline & 11 & $\begin{array}{c}\text { Esplenomegalia, seborréia } \\
\text { seca difusa e vômitos e } \\
\text { diarréia crônicos }\end{array}$ & $\begin{array}{l}\text { CCS, miose, } \\
\quad \text { ceratite } \\
\text { ulcerativa e flare }\end{array}$ & CS, M, PMN \\
\hline & 12 & $\begin{array}{l}\text { Linfadenomegalia, seborréia } \\
\text { seca difusa e onicogrifose }\end{array}$ & $\begin{array}{l}\text { CCS, miose } \\
\text { ceratite } \\
\text { ulcerativa e flare }\end{array}$ & CS, PMN, MN, ER \\
\hline & 13 & $\begin{array}{c}\text { Onicogrifose, diarréia crônica e } \\
\text { seborréia seca difusa }\end{array}$ & CCS & CS, PMN, MN, ER \\
\hline & 14 & $\begin{array}{c}\text { Esplenomegalia, } \\
\text { linfadenomegalia e lesões } \\
\text { cutâneas ulcerativas difusas }\end{array}$ & $\operatorname{ccs}$ & CS, PMN, MN, ER \\
\hline & 15 & $\begin{array}{c}\text { Esplenomegalia e lesões } \\
\text { cutâneas ulcerativas difusas e } \\
\text { diarréia crônica }\end{array}$ & $\operatorname{ccs}$ & CS, M. DC, PMN, ER \\
\hline \multirow{7}{*}{ G2 } & 1 & Onicogrifose & - & PMN \\
\hline & 2 & Linfadenomegalia & - & M raro, DC \\
\hline & 3 & Assintomático & - & PMN \\
\hline & 4 & Seborréia seca difusa & - & PMN \\
\hline & 5 & Seborréia seca difusa & - & CS, PMN \\
\hline & 6 & Linfadenomaglia & - & $\mathrm{M}, \mathrm{DC}$ \\
\hline & 7 & Assintomático & - & CS \\
\hline
\end{tabular}


Tabela 1 (Continuação)

\begin{tabular}{|c|c|c|c|c|}
\hline \multirow{8}{*}{ G2 } & 8 & Linfadenomegalia & - & CS, PMN, DC \\
\hline & 9 & Assintomático & - & CS, PMN, DC \\
\hline & 10 & Assintomático & - & CS, MN \\
\hline & 11 & Assintomático & - & CS, DC \\
\hline & 12 & Seborréia seca difusa & - & CS, PMN \\
\hline & 13 & Linfadenomegalia e apatia & - & $\mathrm{CS}, \mathrm{MN}$ \\
\hline & 14 & Assintomático & - & CS, PMN \\
\hline & 15 & Assintomático & - & $\mathrm{CS}$, muco raro, DC \\
\hline \multirow{5}{*}{ G3 } & 1 & Sadio & - & $\mathrm{CS}, \mathrm{Cl}, \mathrm{CB}, \mathrm{PMN}$ raros \\
\hline & 2 & Sadio & - & $\mathrm{Cl}, \mathrm{CB}$ \\
\hline & 3 & Sadio & - & $\mathrm{CS}, \mathrm{Cl}, \mathrm{CB}$ \\
\hline & 4 & Sadio & - & $\mathrm{Cl}, \mathrm{CB}$ \\
\hline & 5 & Sadio & - & $\mathrm{Cl}, \mathrm{CB}$ \\
\hline
\end{tabular}

Legenda: (-): ausência de sinal ocular; CCS: ceratoconjuntivite seca; flare: turbidez do humor aquoso = aqueous cells; CS: células superficiais (orangeofílicas); M; muco; DC: debris celulares; PMN: células polimorfonucleares; MN: mononucleares; CC: células caliciformes; ER: emperipolese;

$\mathrm{Cl}$ : células intermediárias e CB: células basais.

celular dê indícios da doença, ao compararmos os achados encontrados nos animais do G2 e G3. Não se pretendeu aqui, que a realização deste exame substitua outros exames mais específicos como, por exemplo, a sorologia e exame parasitológico direto, e nem indicá-lo como exame diagnóstico da doença, mas sim, avaliá-lo como método auxiliar de triagem, principalmente, nos casos de animais suspeitos cursando uveíte em áreas epidêmicas e endêmicas, com as vantagens de ser um método rápido, de baixo custo e eficiente.

\section{CONCLUSÕES}

Os resultados observados indicam que a citologia de impressão é um método que permite avaliar a conjuntiva bulbar de cães portadores de Leishmaniose Visceral Canina.

Os achados citopatológicos encontrados em animais sintomáticos, incluindo as uveítes apresentam-se em maior contingente, comparativamente aos animais oligossintomáticos e sadios.

A citologia de impressão da conjuntiva bulbar de cães com uveíte pode ser útil como exame de triagem diagnóstica, porém os exames, parasitológico e sorológico, são imprescindíveis para a confirmação diagnóstica.

\section{AGRADECIMENTOS}

\section{Ao Programa de bolsas PIBIC-CNPq.}

\section{REFERÊNCIAS}

BARROS, J.N. et al. Citologia de impressão de superfície ocular: técnica de exame e de coloração.

Arquivos Brasileiros de Oftalmologia, v.64, n.2, p.127-131, 2001.

BARROS J.N. et al. Avaliação da presença de células caliciformes na córnea humana. Arquivos Brasileiros de Oftalmologia, v.67, n.1, p.121-125, 2004.

BEZERRA, H.L. et al. Utilização da albumina na citologia esfoliativa em pacientes com conjuntivite alérgica. Arquivos Brasileiros de Oftalmologia, v.66, n.6, p.854-858, 2003.

BLAVIER, A. et al. Atypical forms of canine leishmaniosis. Veternary Journal, v.162, n.2, p.108-20, 2001.

BOLZAN, A.A. et al. Citologia conjuntival por impressão na espécie canina. In: ENAPAVE, 11., Botucatu. Resumos ... Botucatu: ENAPAVE, 2003 p.21.

CIARAMELLA, $P$. et al. A retrospective clinical study of canine leishmaniasis in 150 dogs naturally infected by Leishmania infantum. Veterinary Records, v.141, n.21, p.539-543, 1997. 
DART, J. Impression cytology of the ocular surface research tool or routine clinical investigation? British Journal of Ophthalmology, v.81, n.930, 1997.

EGBERT P.; LAUBER S.; MAURICE D.M. A simple conjunctival biopsy. American Journal of Ophthalmology, v.84, n.6, p.798-801, 1977.

FONT, A. et al. Canine mucosal leishmaniasis. Journal of the American Animal Hospital Association, v.32, n.2, p.131-7, 1996.

GARCIA-ALONSO, M. et al. Immunopathology of the uveitis in canine leishmaniasis. Parasite Immunology, v.18, n.2, p.617-623, 1996.

GOMES, J.A.P. Atualização no tratamento das ceratoconjuntivites cicatriciais. Arqquivos Brasileiros de Oftalmologia, v.63, n.1, p.91-96, 2000.

JACKSON, J.A.; PERRIGIN, J.A. Relationship of impression cytology and tear ferning to reports of dry eye. Journal of American Ophthalmology Association, v.70, n.2, p.187-192, 1999.

KIM, J.S. et al. Amniotic membrane patching promotes healing and inhibits proteinase activity on wound healing following acute corneal alkali burn. Experimental Eye Research, v.70, n.3, p.329-37, 2000.

MARTINEZ, A.J. et al. Standardization of conjuntival impression cytology. Cornea, v.14, n.5, p.515-522, 1995.

MARZOCHI, M.C.A. et al. Leishmaniose visceral canina no Rio de Janeiro - Brasil. Cadernos de

Saúde Pública, v.1, n.4, p.432-446, 1985.
POCAI, E. A. et al. Leishmaniose visceral (calazar): cinco casos em cães em Santa Maria, Rio Grande do Sul, Brasil. Ciência Rural, v.28, n.3, p.501-505, 1998.

RIBEIRO, V.M. Leishmaniosis. Revista do Conselho Federal de Medicina Veterinária. v.53, n.11, p.13-14, 1997.

ROCHA, N.S. et al. Citologia de impressão da conjuntiva ocular do homem e do cão. Revista Brasileira de Medicina Veterinária, v.2, n.2, p.5860, 2002.

SANTA ROSA, I.C.A.; OLIVEIRA, I.C.S.

Leishmaniose visceral: breve revisão sobre uma zoonose reemergente. Clínica Veterinária, v.11, p.24-28, 1997.

SLATTER, D. Fundamentos de Oftalmologia Veterinária. São Paulo: Rocca, 2007. 686p.

THIEL, M.A. BOSSART, W.; BERNAUER, W. Improved impression cytologiy techniques for the immunopathological diagnosis of superficial viral infections. British Journal of Ophthalmology, v.81, n.11, p.984-988, 1997.

TSENG, S.C.G. Staging of conjunctival squamous metaplasia by impression cytology. Ophthalmology, v.92, n.6, p.728-733, 1985. 